\title{
Demographic Modeling of a Predator-Prey System and Its implication for the Gombe Population of Procolobus rufomitratus tephrosceles
}

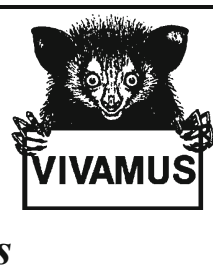

\author{
Marc Fourrier • Robert W. Sussman • \\ Rebecca Kippen • Geoff Childs
}

Received: 17 April 2007 / Accepted: 9 August 2007/

Published online: 1 April 2008

(C) Springer Science + Business Media, LLC 2008

\begin{abstract}
We evaluated the viability of colobus populations under conservative estimates of predation by chimpanzees. If fertility and mortality schedules remain constant, intensely hunted red colobus populations will experience negative growth rates if one allows the assumption of stable age structure to persist into the future. Demographic models have many advantages in studies of primate behavior and ecology. Researchers use them to investigate the quality of observed data and to project population growth rates to changes in mortality, fertility, and migration schedules. We used published age-specific death rates for red colobus (Procolobus rufomitratus tephrosceles) in Gombe National Park, Tanzania, to construct model life tables under various mortality scenarios. Selection in life-history traits toward shorter interbirth intervals, reduction in gestation length, and increased dispersal of individuals from source to sink populations and antipredator behavior, show a limited ability to counter the effects of intense predation. At Gombe, where factors such as small reserve size and isolation prevail, current levels of predation by chimpanzees may depress intrinsic growth rates low enough to cause the extirpation of red colobus in the near future.
\end{abstract}

Keywords chimpanzee $\cdot$ demographic modeling $\cdot$ predation $\cdot$ red colobus

\section{Introduction}

Naturally occurring predator-prey systems are typically complex relationships containing a variety of bottom-up and top-down controls (Raven and Johnson 1989). In the extreme top-down interpretation, predators control prey populations

M. Fourrier $\cdot$ R. W. Sussman $(\bowtie) \cdot$ G. Childs

Anthropology Department, Washington University in St. Louis, St. Louis, MO 63130, USA

e-mail: rwsussma@artsci.wustl.edu

R. Kippen

Demography \& Sociology Program, The Australian National University,

Canberra, ACT 0200, Australia 
and cyclical oscillations of both populations may result depending on the importance of the prey in the diet of the predator. When the breadth of diet is sufficiently wide, the predator may simply keep the prey's numbers low and in equilibrium. Detailed accounts of vertebrate predator-prey systems are rare. Of the ones that exist, most come from outside the Primates: wolves (Mech 1970), hyenas (Kruuk 1972; Mills 1990), African wild dogs (Estes and Goddard 1967), and lions (Schaller 1972).

Predation is an important selective force on the evolution of primate social behavior (Hart 2000; Sterck et al. 1997; van Schaik 1996). It is undoubtedly significant and a leading source of mortality in primate populations (Terborgh 1983). Nevertheless, it has been difficult to estimate the impact of predation on life-history traits and behavior in primates because researchers rarely observe predation events (Hill and Dunbar 1998; Stanford 2002; cf. Hart 2000).

Considerable debate has centered on the importance of predation in the evolution of primate sociality (Cheney et al. 2004). Data from $30 \mathrm{yr}$ of research in Gombe National Park, Tanzania provide a unique opportunity to investigate the consequences of predation ( $c f$. Busse 1977; Goodall 1986; Stanford 1995; Wrangham and van Bergmann-Riss 1990). Long-term research by Goodall (1986) and colleagues on the life history of red colobus (Procolobus rufomitratus tephrosceles) has resulted in good estimates of average fertility and mortality rates, with only a few notable gaps including mean reproductive lifespan, age-specific fertility rates, total fertility rates, and life expectancy. Missing data notwithstanding, the data lend themselves to a model-analysis approach of the possible demographic responses in a primate prey population to predation.

Stanford (1998) compared colobus group sizes both inside and outside chimpanzee hunting ranges at Gombe and found that predation imposes a constraint on the total size of the colobus population. Chimpanzees are thus keystone predators within the Gombe system. However, the effect of predation in colobus ecology remains controversial. In his review of Demonic Males (Wrangham and Peterson 1996), Bernstein (1997) wrote: "The murderous Gombe chimpanzee hunters are said to have killed $30 \%$ of the red colobus monkeys each year for twenty years. Even if this was the only cause of death for red colobus, if half the animals were female and $60 \%$ were reproductive, then each female would have to have one live birth every year just to satisfy the chimpanzees" (p. 153). Yet, red colobus may have responded to chimpanzee predation with just such a shift toward a faster life history and concomitant shifts in shorter interbirth interval, shorter gestation, and nonseasonal reproduction (Stanford 1995, 1998). The fecundity of female red colobus at Gombe is quite high, due to their short interbirth interval and short gestation. Stanford (1998) thought that reproductive patterns may have evolved to counter the effects of severe predation pressure.

Boesch (1994), Boesch et al. (2002), Hosaka et al. (2001), Power (1991), and Sanz (2004) have related dramatic differences in frequency and pattern of red colobus hunting to demography of the predator and prey, chimpanzee party size, number of males in chimpanzee subgroups, hunting behavior of particular individuals, changes in availability of food resources, forest structure, and the amount and quality of human interference. In an earlier study, Hladik (1977) stated 
that in most chimpanzee populations, meat "as a dietary protein complement is of little importance $(<0.5 \%$ of the diet) compared with other types of animal foods, especially ants and termites" (p. 491), which Boesch and Boesch-Achermann (2000) confirmed in estimates of meat intake per day at Gombe and Tai. Individuals that might need it the most, including subadults and nursing females, have no access to meat., Boesch and Boesh-Achermann (2000) believe that meat is not necessary for survival or for normal growth. Generally, captive chimpanzees are reluctant to eat meat and their oral and dental morphologies are not particularly efficient for chewing meat (Milton and Demment 1989). Accordingly, how natural is chimpanzee hunting of red colobus, and how much has human interference and habitat destruction influenced the behavior in recent years?

Hunting classically plays a central role in theories concerning the evolution of human behavior. Researchers often consider cooperative big game hunting and offspring provisioning to be fundamental to human evolution (Dart 1953; Isaac 1978; Lovejoy 1981; Stanford 1999; Stanford and Bunn 2001; Washburn and Lancaster 1968; Wrangham and Peterson 1996). However, they have also questioned the importance of hunting in early human evolution (Binford 1992; Brain 1981; Hart and Sussman 2005; Klein 1989; Zihlman 1997). Thus, because chimpanzee hunting behavior is often central to theories of human evolution and behavior, it is important to consider constraints on life-history traits and population growth in the main chimpanzee prey species before we can understand the role of hunting in shaping primate natural history and models of human evolution.

The role of predation in primate natural history has a rich and long tradition in primatology (Hart 2000; Hart and Sussman 2005). The role of hunting behavior in primate societies is less studied and documented. In chimpanzee society, hunting may serve a socioecological function, with males that hunt holding higher rank within the male hierarchy or gaining reproductive opportunities with estrous females via sharing meat (Stanford 1998; Teleki 1973). However, some researchers have questioned this interpretation (Boesch and Boesch 1989; Mitani et al. 2001, 2002). Furthermore, the frequency of hunting red colobus varies at different sites, with very few or no red colobus hunts occurring at several sites where they are sympatric with chimpanzees (Boesch and Boesch-Achermann 2000; Hunt and McGrew 2002; Newton-Fisher et al. 2002; Sanz 2004). At some sites, the number of red colobus individuals captured and the frequency of red colobus hunting also have dramatically increased over the years. For example, at Gombe, red colobus as prey increased from $64 \%$ to $82 \%$ between $1974-81$ and 1982-91 (Stanford et al. 1994). At Mahale, red colobus made up $14 \%$ of prey species from 1966 to $1981,56 \%$ from 1983 to 1989 , and 83\% from 1990 to 1995 (Hosaka et al. 2001). Concurrently, the number of individuals captured of other prey species changed little.

We used red colobus life-history parameters from the Gombe literature to construct model life tables. Our goal was not only to assess the impact of intense predation on local populations, but also to address the adaptive explanations for the persistence of colobus populations under predation pressure. In addition, we hope to contribute to an increasingly important literature using demographic modeling in studies of selective responses to ecological problems. 


\section{Methods}

Model demographic systems have proven their worth in human demography. For example, model life tables can help to uncover age-specific patterns in mortality when overall mortality is the only datum available (Gage 1998). Another advantage to demographic modeling is its ability to assess the quality of empirical demographic data. "A set of data that cannot be fitted well should be treated with suspicion since, although a poor fit does not, of course, constitute absolute proof of the existence of errors or omissions, it does indicate that more careful investigation, or at the very least caution in analysis, is necessary" (Newell 1988, p. 118).

Modeling also lends itself to simulating population trends under hypothetical fertility and mortality schedules. Projecting the size of a future population typically requires using existing data for known parameters and estimating parameters difficult to measure, such as age-cohort mortalities. The approach, when used with multiple, age-structured fertility, mortality, or dispersal scenarios, can provide information on unknown life-history parameters given a desired rate of population growth or size.

A population's stable structure is a deterministic function of its mortality and fertility schedules, in the absence of dispersal. In a stable population, the size of an age class relative to the total population remains constant until a change in either the mortality or fertility schedules is introduced. A stable population has a constant growth rate, which may be positive, negative, or 0 , the last giving rise to a unique case known as a stationary population.

We used observed age-specific probabilities of dying from a long-term study of red colobus groups in Gombe National Park (Stanford 1995, 1998; Table 1). The mortality probabilities are denoted in life tables as $q x=D x / N x$, with $D x$ equal to deaths between exact age $x$ and exact age $x+1$ and $N x$ equal to the population exact aged $x$ at the start of the interval. The data are unique in that they are remarkably detailed in discriminating between predatory and nonpredatory rates of mortality for a wild population of primates. Mortality rates for ages $>54$ mo are missing and age intervals are in 6-mo periods. We continued to use 6-mo intervals as years matching the resolution of the data.

We created 6 mortality assumptions from the age-specific death rate (ASDR) data, 3 hunted (high) and 3 nonhunted (low). In certain assumptions, an additional variable was fixed. We used a rate of 0.40 mortality for the interval of $x=180$

Table 1 Probability of dying per age class in hunted and nonhunted colobus populations

Data from Stanford (1998).

를 Springer

\begin{tabular}{lll}
\hline \multirow{2}{*}{$\begin{array}{ll}\text { Age intervals } \\
\text { (mo) }\end{array}$} & $q x$ values & \\
\cline { 2 - 3 } & Total (including hunted probabilities) & Nonhunted \\
\hline $0-5$ & 0.313 & 0.137 \\
$6-11$ & 0.171 & 0.085 \\
$12-17$ & 0.138 & 0.069 \\
$18-23$ & 0.280 & 0.120 \\
$24-29$ & 0.278 & 0.167 \\
$30-35$ & 0.077 & 0.000 \\
$36-41$ & 0.000 & 0.000 \\
$42-47$ & 0.100 & 0.000 \\
$48-53$ & 0.111 & 0.111
\end{tabular}


185 mo to pull down adult mortality rates $(>54 \mathrm{mo})$ in the smoothing method. We use the term pull in the tables because the fixed value effectively pulls the curve down to conservative adult mortalities resembling the typical age pattern of high mortality in infancy, dropping to low levels in adolescence and adulthood, and then rising again in later years ( $c f$. Gage 1998, p. 204). We referenced the literature from outside Gombe to estimate the oldest age category for a colobus in our mortality tables. We chose a conservative estimate of $16.0 \mathrm{yr}(192 \mathrm{mo})$ for the absolute oldest age of an individual in the population. We derived the estimate by taking the longest reproductive lifespan for a female red colobus (12.25 yr) that Struhsaker and Pope (1991) observed in Kibale, Uganda, and adding $3 \mathrm{yr}$, the age at reproductive onset that Stanford (1998) reported. Therefore in our tables, we set the probability of dying after survival to 186 mo to 1.00 .

Within both high and low assumptions, we smoothed the ASDR data by fitting to a quadratic model containing both a first- and second-order term: $Y=$ $a_{0}+a_{1} X+a_{2} X^{2}$, wherein $Y$ is $q x$ and $X$ is the number of months at the beginning of the interval. We accomplished fitting via least-squares regression. By generating predicted values from the best fit model, we derived 2 mortality schedules for both the hunted and nonhunted populations. We generated the first directly from the raw data. The second is from the raw data plus the fixed value in the 180-185 mo interval. In addition, we consider a third assumption for each population. Wild populations of red colobus may experience a close to 0 mortality for much of their lives after the high mortality of the infant and adolescent stages. We therefore constructed mortality schedules that assumed all individuals surviving $>54$ mo are subsequently exposed to 0 mortality up to the interval of $180-185$ at which time all individuals die. Though this is an unlikely assumption, it is a conservative one for our purposes, giving the population its greatest chance of survival under the observed mortality in the infant and adolescent stages.

Wild populations of monkeys show varied female fertility schedules. Where researchers have described the demographic characteristics of captive macaques, 2 general patterns of fertility have emerged. In some cases, age-specific fertility rates (ASFRs, defined as the number of births in the age interval $x$ divided by the population age $x$ at the midpoint of the age interval) increase to a peak at some time after the onset of fertility, followed by a gradual decrease toward reproductive senescence (Macaca nemestrina: Ha et al. 2000). In other cases, fertility schedules show a more uniform distribution throughout the reproductive lifespan of females (Macaca radiata: Silk et al. 1981).

In Gombe and Kibale, Uganda, where female red colobus disperse from their natal groups as they approach reproductive maturity, age-specific fecundity estimates are imprecise (T. T. Struhsaker, pers. comm.). It is nevertheless common in field studies of wild primates, in which ages of adults are rarely known, to measure average female fertility rates in terms of total number of annual births divided by the number of females of reproductive age in the population. The measurement naturally incorporates both fecund and nonfecund females, thereby incorporating a degree of natural infertility in the population where it exists.

We developed 3 fertility assumptions for Gombe red colobus. Two of them bracket the range of observed values of female fertility from Stanford (1998) across all reproductive age categories, $0.496-0.625$ births/female/ yr. The values corre- 
spond to an interbirth interval of 24.2-19.2 mo, which in turn translates to 6-mo female fertility rates of 0.2479 and 0.3125 births/female. We argue that one should consider an average, uniform distribution of ASFR across all female age categories a conservative approach in that it consistently overestimates the total fertility rate (TFR) compared to the typical age-specific fertility patterns in monkey populations.

To address the effect of a drastic adjustment to the interbirth interval in response to intense predation, we developed a third fertility assumption whereby each female gave birth every $9 \mathrm{mo}$, translating to a 6-mo female fertility rate of 0.666 births/ female. The interval reflects the shortest one for red colobus at Gombe (Stanford 1995; $N=8$ ), and occurred after the death of the infant due to predation. In our assumptions, females conservatively first reproduce at $x=36-41 \mathrm{mo}$, corresponding to the earliest reported event in colobus at Gombe (Stanford 1998), and continue to reproduce until their death, maximum $x=186-191$ mo.

We constructed only female life history tables because the demographic characteristics of females, i.e., age at onset of reproduction, rates of fertility, and reproductive lifespan, are more likely to limit the growth of the population than are characteristics of males. In doing so, we assumed mortality rates were independent of sex and the sex ratio at birth is equal to 1 . The assumptions result in identical male and female life tables. The first assumption is reasonable, at least for infant and adolescent categories, because predation is indiscriminately distributed between males and females (Stanford 1998). As for the second, we have no reason to believe that the sex ratio at birth is anything but 1 . Given our use of only female life tables, we adjusted our 6-mo female fertility assumptions to $0.1240,0.1563$, and 0.3333 female births/female, referred to as low-fertility, high-fertility, and super-fertility, respectively, in all tables. Table 2 contains our 6 mortality and 3 fertility assumptions.

We used an iterative approach to calculate the intrinsic rate of natural increase, $r$, for the 18 possible scenarios ( 6 mortality assumptions $\times 3$ fertility assumptions). We initially seeded populations with a uniform distribution of 1000 females in each 6-mo category. We then allowed each combination of mortality and fertility assumptions to operate on the population for 50 iterations, the equivalent of $25 \mathrm{yr}$. We then calculated the intrinsic rate of increase directly from the resulting population.

\section{Results}

$p_{x}$ is the probability of surviving between exact age $x$ and exact age $x+1 . l_{x}$ is the number of individuals that survive to exact age $x$ and is equal to $\left(l_{x-1}\right)\left(p_{x-1}\right) \cdot d_{x}$ is the number of individuals dying between exact age $x$ and exact age $x+1$ and is therefore equal to the algebraic difference between $l_{x}$ and $l_{x+1} . L_{x}$ is the total number of monkey 6-mo years the life-table population lived between exact age $x$ and exact age $x+1$. It requires an estimate of $a_{x}$, which is the average proportion of the time lived in the age interval $x$ to $x+1$ by those that die during the interval. We assumed that deaths were evenly distributed within an age interval and therefore $a_{x}=0.5$ for all age intervals, including the infant and adolescent intervals $(0-54 \mathrm{mo})$, and so $L_{x}=$ $0.5\left(l_{x}+l_{x+1}\right)$. We calculated $L x$ values from the mortality data $(q x)$ via the preceding equations. $L x$ values were then available for our simulations in the form of survival 
Table 2 Six mortality and 3 fertility assumptions for projection scenarios

\begin{tabular}{|c|c|c|c|c|c|c|c|c|c|}
\hline \multirow{2}{*}{$\begin{array}{l}\text { Age interval } \\
\text { (in mo) }\end{array}$} & \multicolumn{6}{|c|}{ Mortality: $q x$} & \multicolumn{3}{|c|}{ Fertility: $f x$} \\
\hline & High & $\begin{array}{l}\text { High } \\
\text { with pull }\end{array}$ & $\begin{array}{l}\text { High } \\
\text { with pull, } \\
0 \text { adult }\end{array}$ & Low & $\begin{array}{l}\text { Low } \\
\text { with pull }\end{array}$ & $\begin{array}{l}\text { Low } \\
\text { with pull, } \\
0 \text { adult }\end{array}$ & $\begin{array}{l}\text { Low- } \\
\text { fertility }\end{array}$ & $\begin{array}{l}\text { High- } \\
\text { fertility }\end{array}$ & $\begin{array}{l}\text { Super- } \\
\text { fertility }\end{array}$ \\
\hline Assumptions & 1 & 2 & 3 & 4 & 5 & 6 & 7 & 8 & 9 \\
\hline $0-5$ & 0.293 & 0.332 & 0.332 & 0.141 & 0.182 & 0.182 & 0 & 0 & 0 \\
\hline $6-11$ & 0.249 & 0.279 & 0.279 & 0.116 & 0.146 & 0.146 & 0 & 0 & 0 \\
\hline $12-17$ & 0.209 & 0.229 & 0.229 & 0.094 & 0.114 & 0.114 & 0 & 0 & 0 \\
\hline $18-23$ & 0.173 & 0.183 & 0.183 & 0.075 & 0.086 & 0.086 & 0 & 0 & 0 \\
\hline $24-29$ & 0.142 & 0.142 & 0.142 & 0.060 & 0.060 & 0.060 & 0 & 0 & 0 \\
\hline $30-35$ & 0.116 & 0.105 & 0.105 & 0.049 & 0.038 & 0.038 & 0 & 0 & 0 \\
\hline $36-41$ & 0.094 & 0.072 & 0.072 & 0.041 & 0.019 & 0.019 & 0.1230 & 0.1563 & 0.3333 \\
\hline $42-47$ & 0.076 & 0.043 & 0.043 & 0.037 & 0.003 & 0.003 & 0.1230 & 0.1563 & 0.3333 \\
\hline $48-53$ & 0.063 & 0.018 & 0.018 & 0.036 & 0.000 & 0.000 & 0.1230 & 0.1563 & 0.3333 \\
\hline $54-59$ & 0.055 & 0.000 & 0.000 & 0.039 & 0.000 & 0.000 & 0.1230 & 0.1563 & 0.3333 \\
\hline $60-65$ & 0.051 & 0.000 & 0.000 & 0.046 & 0.000 & 0.000 & 0.1230 & 0.1563 & 0.3333 \\
\hline $66-71$ & 0.051 & 0.000 & 0.000 & 0.056 & 0.000 & 0.000 & 0.1230 & 0.1563 & 0.3333 \\
\hline $72-77$ & 0.056 & 0.000 & 0.000 & 0.069 & 0.000 & 0.000 & 0.1230 & 0.1563 & 0.3333 \\
\hline $78-83$ & 0.065 & 0.000 & 0.000 & 0.086 & 0.000 & 0.000 & 0.1230 & 0.1563 & 0.3333 \\
\hline $84-89$ & 0.079 & 0.000 & 0.000 & 0.107 & 0.000 & 0.000 & 0.1230 & 0.1563 & 0.3333 \\
\hline $90-95$ & 0.097 & 0.000 & 0.000 & 0.131 & 0.000 & 0.000 & 0.1230 & 0.1563 & 0.3333 \\
\hline 96-101 & 0.120 & 0.000 & 0.000 & 0.159 & 0.007 & 0.000 & 0.1230 & 0.1563 & 0.3333 \\
\hline $102-107$ & 0.147 & 0.000 & 0.000 & 0.190 & 0.023 & 0.000 & 0.1230 & 0.1563 & 0.3333 \\
\hline $108-113$ & 0.179 & 0.001 & 0.000 & 0.224 & 0.043 & 0.000 & 0.1230 & 0.1563 & 0.3333 \\
\hline $114-119$ & 0.215 & 0.022 & 0.000 & 0.263 & 0.066 & 0.000 & 0.1230 & 0.1563 & 0.3333 \\
\hline $120-125$ & 0.256 & 0.048 & 0.000 & 0.305 & 0.092 & 0.000 & 0.1230 & 0.1563 & 0.3333 \\
\hline $126-131$ & 0.301 & 0.077 & 0.000 & 0.350 & 0.122 & 0.000 & 0.1230 & 0.1563 & 0.3333 \\
\hline $132-137$ & 0.350 & 0.111 & 0.000 & 0.399 & 0.154 & 0.000 & 0.1230 & 0.1563 & 0.3333 \\
\hline $138-143$ & 0.404 & 0.149 & 0.000 & 0.451 & 0.190 & 0.000 & 0.1230 & 0.1563 & 0.3333 \\
\hline $144-149$ & 0.463 & 0.191 & 0.000 & 0.508 & 0.230 & 0.000 & 0.1230 & 0.1563 & 0.3333 \\
\hline $150-155$ & 0.526 & 0.237 & 0.000 & 0.567 & 0.272 & 0.000 & 0.1230 & 0.1563 & 0.3333 \\
\hline $156-161$ & 0.594 & 0.288 & 0.000 & 0.630 & 0.318 & 0.000 & 0.1230 & 0.1563 & 0.3333 \\
\hline $162-167$ & 0.665 & 0.342 & 0.000 & 0.697 & 0.367 & 0.000 & 0.1230 & 0.1563 & 0.3333 \\
\hline $168-173$ & 0.742 & 0.401 & 0.000 & 0.767 & 0.419 & 0.000 & 0.1230 & 0.1563 & 0.3333 \\
\hline $174-179$ & 0.823 & 0.464 & 0.000 & 0.841 & 0.474 & 0.000 & 0.1230 & 0.1563 & 0.3333 \\
\hline $180-185$ & 0.908 & 0.531 & 0.000 & 0.918 & 0.533 & 0.000 & 0.1230 & 0.1563 & 0.3333 \\
\hline 186-191 & 1.000 & 1.000 & 1.000 & 1.000 & 1.000 & 1.000 & 0.1230 & 0.1563 & 0.3333 \\
\hline $192-197$ & 0.000 & 0.000 & 0.000 & 0.000 & 0.000 & 0.000 & 0.0000 & 0.0000 & 0.0000 \\
\hline
\end{tabular}

ratios, i.e., $L x+1 / L x=$ survival ratio for $t=x$. Values after 50 iterations converged to the stable age structure. The $r$ value converges to a value in the high-fertility assumption across each of the 6 mortality assumptions (Fig. 1). We calculated intrinsic rates of growth from each of the 18 scenarios (Table 3 ).

Intrinsic rates of natural increase for hunted populations (high mortality) were $<0$ across the fertilities common in Gombe red colobus (range: -0.087 to -0.012 for 19.2-24.2 mo interbirth intervals), making the populations unlikely to persist. Only under low mortality, i.e., nonhunted, with moderate to 0 deaths in the adult categories, combined with the average observed fertility assumptions do our populations display a positive rate of growth. An interbirth interval of 19.1 mo represents the average interbirth interval after an infant mortality, and 9.0 mo is the shortest interbirth interval after an infant's death (Stanford 1998). Though super- 
Fig. 1 High fertility scenarios across 6 mortality assumptions showing convergence of intrinsic rate of growth.

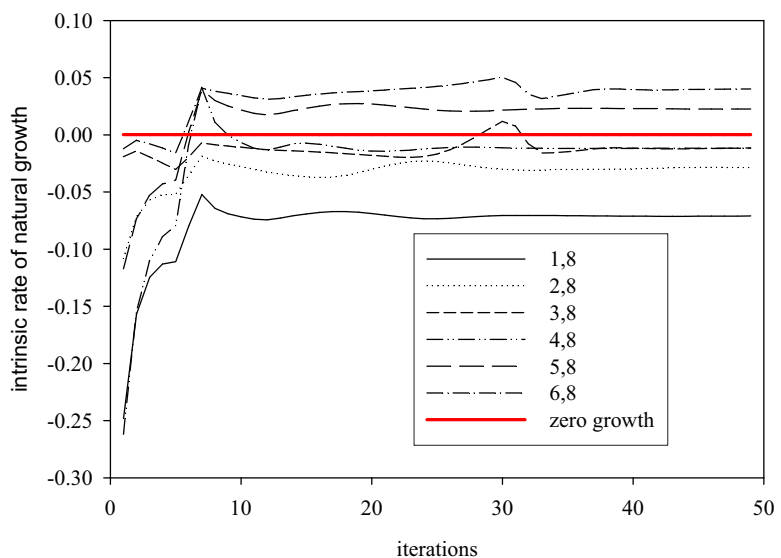

fertile populations display positive growth in virtually all hunted and nonhunted scenarios, they are not likely to be a feasible response to intense predation in that it must be preceded by early infant death.

\section{Discussion}

Primate populations exhibit remarkable plasticity in life-history traits such as age at reproductive maturity, survival, or adult fertility (Pereira and Leigh 2003). We used what is known of the traits in red colobus for 1 locale in Africa and developed a number of assumptions bracketing known values to project future population sizes. We constructed the models for a population of both hunted and nonhunted red colobus between 1991 and 1993 (Stanford 1995). In life-table models the population is arbitrary and may be related to any level of biological organization. For example, the population is any collection of individuals, and can be a subgroup of individuals, the group, a population of groups, the species, etc. Here we used the multimale, multifemale, patrilocal group of red colobus as the population. Our results suggest that for a broad range of natural fertility rates, hunted groups of monkeys are unsustainable.

Table 3 Intrinsic rates of natural growth for 18 scenarios ( 6 mortality assumptions $\times 3$ fertility assumptions)

\begin{tabular}{llcc}
\hline & Low fertility & High fertility & Super fertility \\
\hline Total fertility rate & 6.39 & 8.13 & 17.33 \\
Gross reproduction rate & 3.20 & 4.06 & 8.67 \\
Growth rate in 6 mo & Low fertility & High fertility & Super fertility \\
High mortality & -0.087 & -0.071 & -0.017 \\
High mortality with pull & -0.042 & -0.029 & 0.018 \\
High mortality with pull, 0 adult mortality & -0.024 & -0.012 & 0.032 \\
Low mortality & -0.031 & -0.012 & 0.054 \\
Low mortality with pull & 0.006 & 0.023 & 0.081 \\
Low mortality with pull, 0 adult mortality & 0.025 & 0.040 & 0.092 \\
\hline
\end{tabular}


Role of Increased Reproductive Output of Gombe Red Colobus

Are red colobus able to escape extirpation from the very intense levels of predation, which yearly ranges from 16 to $40 \%$ of the population (Stanford 1996, 1998; Wrangham and van Bergmann-Riss 1990), by increasing reproductive output either via earlier maturation or shorter interbirth intervals? If, for example, all young individuals in a hunted red colobus group are exposed to a certain level of predation risk, then simply having more sequential single offspring per mother should not increase the probability that any individual survives a critical period of its life. "Relying on fecundity as an antipredator mechanism is tantamount to relying on chance (i.e., production of many young must increase the chance that some will not be eaten)." (Matter and Mannan 2005, p. 1318). In lieu of any statistical advantage, a prey must have some behavioral, habitat, or morphological variation that increases the chance to avoid predation. It appears that shortening interbirth intervals is not enough.

\section{Role of the Red Colobus Metapopulation in Gombe}

There is increasing research interest in the role of metapopulations - the total population of a species in a region versus populations in particular circumscribed areas - in the persistence of predator-prey interactions. An especially popular application of the use of the concept of metapopulations has been in the context of predator-prey interactions as a way of reconciling their persistence in nature with the fact that spatially simple predator-prey systems, both in the laboratory and in models, tend to be unstable to the point of extinction (Taylor 1990). Dispersal among populations may allow for the persistence of populations that otherwise experience unstable fluctuations and local extinctions. Despite long-term studies on predatorprey systems, evidence of the importance of dispersal is largely indirect.

We have assumed immigration and emigration are identical. While unrealistic, the assumption permits us to investigate the potential consequences of hunting at the group level. In all but the most fertile (and perhaps unrealistic) populations, predation resulted in negative growth trends.

The most likely role of dispersal in such scenarios is one in which movement from source populations allows hunted populations to persist. Some background is informative here. Gombe National Park is located in the Kigoma Rural District in western Tanzania, a district with $>1$ million inhabitants. It is a mere $32 \mathrm{~km}^{2}$ and contains ca. 150 chimpanzees. Today, Gombe is an isolated island of forest surrounded by a deforested landscape (Campbell 2001). Given that, ecologically speaking, red colobus are specialists that reside in core forest habitat, it is unlikely that anything but relic populations of red colobus monkeys exist outside the park.

According to stable population theory, with constant below-replacement fertility, i.e., deaths exceed births, constant mortality, and constant positive net migration, a population will converge to stationarity (Espenshade et al. 1982). That is, the population will assume a constant age structure and 0 population growth, irrespective of the imbalance between births and deaths and no matter the level of net migration, so long as it is positive. In our modeled, predated colobus populations, without migrants, the population would have negative growth rates 
and eventually disappear. However, because the population is supplemented by inflows, the result may be a fairly stationary population if the inflows are fairly constant. However, in Gombe, the condition of constant positive net migration from outside the hunted colobus populations is probably not met, making a stationary population unlikely in the long-term.

In his study of predator-prey relations, Schaller (1972) concluded that predation by Serengeti lions is not a limiting factor on prey populations because lions often take the surplus individuals that are less fit. While the notion that predators rarely cause the extinction of coevolved prey is a very real one, we argue that a natural predator-prey interaction has an ecological context and that when that context is altered, e.g., via a landscape level conversion of habitat to degraded states, the evolved interaction must find a new equilibrium or cease to exist. It is that sort of extirpation that we believe is happening to the red colobus in Gombe, in the absence of a greater colobus metapopulation.

Given our results, the current predator-prey interactions between chimpanzees and red colobus at Gombe could not have existed for many years in the past, and can persist for only a short time into the future. We offer the hypothesis that the unusually high predation rates on this red colobus population are not natural and have been caused by recent changes to the habitat and related demographic changes to both the chimpanzee and red colobus populations.

Acknowledgments We thank Donna Hart and 2 anonymous reviewers for very helpful suggestions on the manuscript.

\section{References}

Bernstein, I. S. (1997). One man's view. American Journal of Primatology, 41, 151-154.

Binford, L. (1992). Subsistence - a key to the past. In S. Jones, R. Martin, \& D. Pilbeam (Eds.) Cambridge encyclopedia of human evolution (pp. 365-368). Cambridge, U.K.: Cambridge University Press.

Boesch, C. (1994). Hunting strategies of Gombe and Taï chimpanzees. In R. Wrangham, W. McGrew, F. de Waal, \& P. Heltne (Eds.) Chimpanzee cultures (pp. 77-92). Cambridge, MA: Harvard University Press.

Boesch, C., \& Boesch, H. (1989). Hunting behavior of wild chimpanzees in the Taï National Park, Ivory Coast. American Journal of Physical Anthropology, 78, 547-574.

Boesch, C., \& Boesch-Achermann, H. (2000). The chimpanzees of the Taï forest: Behavioural ecology and evolution. Oxford, U.K.: Oxford University Press.

Boesch, C., Uehara, S., \& Ihobe, H. (2002). Variations in chimpanzee-red colobus interactions. In C. Boesch, G. Hohmann, \& L. F. Marchant (Eds.) Behavioural diversity in chimpanzees and bonobos (pp. 221-230). Cambridge, U.K.: University of Cambridge Press.

Brain, C. K. (1981). The hunters or the hunted. Chicago: University of Chicago Press.

Busse, C. D. (1977). Chimpanzee predation as a possible factor in the evolution of red colobus monkey social organization. Evolution, 31, 907-911.

Campbell, M. M. (2001). Pachyderms, primates, plants and population. Reproduction, Fertility and Development, 13, 697-703.

Cheney, D. L., Seyfarth, R. M., Fischer, J., Beehner, J., Bergman, T., Johnson, S. E., et al. (2004). Factors affecting reproduction and mortality among baboons in the Okavango Delta, Botswana. International Journal of Primatology, 25, 401-428.

Dart, R. (1953). The predatory transition from ape to man. International Anthropological and Linguistic Review, 1, 201-217. 
Espenshade, T. J., Bouvier, L. F., \& Arthur, W. B. (1982). Immigration and the stable population model. Demography, 19, 125-133.

Estes, R. D., \& Goddard, J. (1967). Prey selection and hunting behaviour of the African wild dog. Journal of Wildlife Management, 31, 52-70.

Gage, T. B. (1998). The comparative demography of primates: With some comments on the evolution of life histories. Annual Review of Anthropology, 27, 197-221.

Goodall, J. (1986). The chimpanzees of Gombe: Patterns of behavior. Cambridge, MA: Harvard University Press.

Ha, J. C., Robinette, R. L., \& Sackett, R. L. (2000). Demographic analysis of the Washington regional primate research center pigtailed macaque colony, 1967-1996. American Journal of Primatology, 52, $187-198$.

Hart, D. (2000). Primates as prey: Ecological, morphological, and behavioral relationships between primates and their prey. Ph.D. dissertation, Washington University, Saint Louis, MO.

Hart, D., \& Sussman, R. W. (2005). Man the hunted: primates, predators, and human evolution. Boulder, CO: Westview Press.

Hill, R. A., \& Dunbar, R. I. M. (1998). An evaluation of the roles of predation rate and predation risk as selective pressures on primate grouping behaviour. Behaviour, 135, 411-430.

Hladik, C. M. (1977). Chimpanzees of Gabon and chimpanzees of Gombe: Some comparative data on the diet. In T. H. Clutton-Brock (Ed.) Primate ecology: Studies of the feeding and ranging behaviour in lemurs, monkeys and apes (pp. 481-501). New York: Academic Press.

Hosaka, K., Nishida, T., Hamai, M., Matsumoto-Oda, A., \& Uehara, S. (2001). Predation of mammals by the chimpanzees of the Mahale Mountains, Tanzania. In M. F. Galdikas Biruté, N. Erickson Briggs, L. K. Sheeran, G. L. Shapiro, \& J. Goodall (Eds.) All apes great and small, vol. 1: African apes (pp. 107-130). New York: Kluwer Academic.

Hunt, K. D., \& McGrew, W. C. (2002). Chimpanzees in the dry habitats at Mount Assirik, Senegal and at the Semliki-Toro Wildlife Reserve, Uganda. In C. Boesch, G. Hohmann, \& L. F. Marchant (Eds.) Behavioural diversity in chimpanzees and bonobos (pp. 35-51). Cambridge, U.K.: University of Cambridge Press.

Isaac, G. L. (1978). The food-sharing behavior of proto-human hominids. Scientific American, 238, 90-108.

Klein, R. G. (1989). The human career: Human biological and cultural origins. Chicago: University of Chicago Press.

Kruuk, H. (1972). The spotted hyena. Chicago: University of Chicago Press.

Lovejoy, C. O. (1981). The origin of man. Science, 211, 341-350.

Matter, W. J., \& Mannan, R. W. (2005). How do prey persist. Journal of Wildlife Management, 69, 13151320 .

Mech, D. L. (1970). The wolf. New York: Natural History Press.

Mills, M. G. L. (1990). Kalahari hyenas: The Comparative behavioural ecology of two species. London, U.K.: Chapman and Hall.

Milton, K., \& Demment, M. (1989). Features of meat digestion by captive chimpanzees (Pan troglodytes). American Journal of Physical Anthropology, 18, 45-52.

Mitani, J. C., Watts, D. P., \& Muller, M. N. (2001). Why do chimpanzees hunt and share meat. Behaviour, 59, 915-924.

Mitani, J. C., Watts, D. P., \& Muller, M. N. (2002). Recent developments in the study of wild chimpanzee behavior. Evolutionary Anthropology, 11, 9-25.

Newell, C. (1988). Methods and models in demography. New York: The Guilford Press.

Newton-Fisher, N. E., Notman, H., \& Reynolds, V. (2002). Hunting of mammalian prey by Budongo forest chimpanzees. Folia Primatologica, 73, 281-283.

Pereira, M. E., \& Leigh, S. R. (2003). Modes and phases of primate juvenility. In P. M. Kappeler, \& M. E. Pereira (Eds.) Primate life histories and socioecology (pp. 149-176). Chicago: University of Chicago Press.

Power, M. (1991). The egalitarians, human and chimpanzee: An anthropological view of social organization. Cambridge, U.K.: Cambridge University Press.

Raven, P. H., \& Johnson, G. B. (1989). Biology. Saint Louis, MO: Times Mirror/Mosby College Publishing.

Sanz, C. M. (2004). The Behavioral ecology of chimpanzees in a Central African forest: Pan troglodytes troglodytes in the Goualougo triangle, Republic of Congo. Ph.D. dissertation, Washington University, Saint Louis, MO.

Schaller, G. B. (1972). The serengeti lion. Chicago: University of Chicago Press. 
Silk, J. B., Clark-Wheatley, C. B., \& Rodman, P. S. (1981). Differential reproductive success and facultative adjustment of sex ratios among captive female bonnet macaques (Macaca radiata). Animal Behavior, 29, 1106-1120.

Stanford, C. B. (1995). The influence of chimpanzee predation on group size and anti-predator behaviour in red colobus monkeys. Animal Behavior, 49, 577-587.

Stanford, C. B. (1996). The hunting ecology of wild chimpanzees: Implications for the behavioral ecology of Pliocene hominids. American Anthropologist, 98, 96-113.

Stanford, C. B. (1998). Chimpanzee and red colobus: The ecology of predator and prey. Cambridge, MA: Harvard University Press.

Stanford, C. B. (1999). The hunting ape: Meat eating and the origins of human behavior. Princeton: Princeton University Press.

Stanford, C. B. (2002). Avoiding predators: Expectations and evidence in primate antipredator behavior. International Journal of Primatology, 23, 741-757.

Stanford, C. B., \& Bunn, H. T. (2001). Meat eating and human evolution. Oxford, U.K: Oxford University Press.

Stanford, C. B., Wallis, J., Matama, H., \& Goodall, J. (1994). Patterns of predation by chimpanzees on red colobus monkeys in Gombe National Park, Tanzania, 1982-1991. American Journal of Physical Anthropology, 94, 213-228.

Sterck, E. H. M., van Schaik, C. P., \& Watts, D. P. (1997). The evolution of female social relationships in nonhuman primates. Behavioural Ecology and Sociobiology, 41, 291-309.

Struhsaker, T. T., \& Pope, T. R. (1991). Mating system and reproductive success: A comparison of two African forest monkeys (Colobus badius and Cercopithecus ascanius). Behaviour, 117, 182-205.

Taylor, A. D. (1990). Metapopulations, dispersal, and predator-prey dynamics: An overview. Ecology, 71, 429-433.

Teleki, G. (1973). The predatory behavior of wild chimpanzees. Lewisburg, PA: Bucknell University Press.

Terborgh, J. (1983). Five new world primates: A study in comparative ecology. Princeton: Princeton University Press.

van Schaik, C. P. (1996). Social evolution in primates: The role of ecological factors and male behaviour. Proceedings of the British Academy, 88, 9-31.

Washburn, S. L., \& Lancaster, C. S. (1968). The evolution of hunting. In R. B. Lee, \& I. De Vore (Eds.) Man the hunter (pp. 293-303). Chicago: Aldine.

Wrangham, R. W., \& Peterson, D. (1996). Demonic males: Apes and the origins of human violence. Boston: Houghton Mifflin.

Wrangham, R. W., \& van Bergmann-Riss, E. Z. (1990). Rates of predation on mammals by Gombe chimpanzees, 1972-1975. Primates, 31, 157-170.

Zihlman, A. (1997). The Paleolithic glass ceiling: Woman in human evolution. In L. Hager (Ed.)Women in human evolution (pp. 91-113). London: Routledge. 